\title{
Corrigendum: Bacillus velezensis FZB42 in 2018: The Gram-Positive Model Strain for Plant Growth Promotion and Biocontrol
}

\author{
Ben Fan ${ }^{1 *}$, Cong Wang ${ }^{2}$, Xiaofeng Song ${ }^{2}$, Xiaolei Ding ${ }^{1}$, Liming $W u^{3}$, Huijun $W u^{3}$, \\ Xuewen $\mathrm{Gao}^{3}$ and Rainer Borriss ${ }^{4,5 *}$ \\ ${ }^{1}$ Co-Innovation Center for Sustainable Forestry in Southern China, College of Forestry, Nanjing Forestry University, Nanjing, \\ China, ${ }^{2}$ Department of Biomedical Engineering, Nanjing University of Aeronautics and Astronautics, Nanjing, China, \\ ${ }^{3}$ Department of Plant Pathology, College of Plant Protection, Nanjing Agricultural University, and Key Laboratory of Integrated \\ Management of Crop Diseases and Pests, Ministry of Education, Nanjing, China, ${ }^{4}$ Institut für Biologie, Humboldt Universität \\ Berlin, Berlin, Germany, ${ }^{5}$ Nord Reet UG, Greifswald, Germany
}

Keywords: Bacillus velezensis, FZB42, AmyloWiki, induced systemic resistance (ISR), non-ribosomal synthesized lipopeptides (NRPS), non-ribosomal synthesized polyketides (PKS), volatiles, plant growth promoting bacteria (PGPR)

\section{OPEN ACCESS}

Edited and reviewed by: Brigitte Mauch-Mani, Université de Neuchâtel, Switzerland

*Correspondence: Ben Fan

fanben2000@gmail.com Rainer Borriss rainer.borriss@rz.hu-berlin.de

Specialty section: This article was submitted to Plant Microbe Interactions, a section of the journal

Frontiers in Microbiology

Received: 19 April 2019 Accepted: 22 May 2019

Published: 11 June 2019

Citation:

Fan $B$, Wang $C$, Song $X$, Ding $X$, Wu L, Wu H, Gao $X$ and Borriss $R$

(2019) Corrigendum: Bacillus

velezensis FZB42 in 2018: The Gram-Positive Model Strain for Plant Growth Promotion and Biocontrol. Front. Microbiol. 10:1279. doi: 10.3389/fmicb.2019.01279

\section{A Corrigendum on}

Bacillus velezensis FZB42 in 2018: The Gram-Positive Model Strain for Plant Growth Promotion and Biocontrol

by Fan, B., Wang, C., Song, X., Ding, X., Wu, L., Wu, H., et al. (2018). Front. Microbiol. 9:2491. doi: 10.3389/fmicb.2018.02491

In the original article, there was an error in referring to the approved group of Bacillus cereus.

A correction has been made to the Conclusion and Outlook section, "(1) Apathogenicity":

"(1) Apathogenicity: Concerning biosafety issues, no representatives of the B. subtilis species complex including B. velezensis have been listed as risk group in 'The Approved List of biological agents' (Advisory Committee on Dangerous Pathogens, 2013). By contrast, use of strains of B. cereus needs special attention, since they are a member of risk group 2 and closely related to B. anthracis, a human pathogen and the member of risk group 3."

The authors apologize for this error and state that this does not change the scientific conclusions of the article in any way.

\section{REFERENCES}

Advisory Committee on Dangerous Pathogens (2013). The Approved List of Biological Agents. Available online at: www.hse.
gov.uk/pubns/misc208.htm

Copyright (c) 2019 Fan, Wang, Song, Ding, Wu, Wu, Gao and Borriss. This is an open-access article distributed under the terms of the Creative Commons Attribution License (CC BY). The use, distribution or reproduction in other forums is permitted, provided the original author(s) and the copyright owner(s) are credited and that the original publication in this journal is cited, in accordance with accepted academic practice. No use, distribution or reproduction is permitted which does not comply with these terms. 